УДК 624.131

\title{
КЛАССИФИЦИРОВАНИЕ ПО КОНСИСТЕНЦИИ ОРГАНОМИНЕРАЛЬНЫХ ГРУНТОВ ЗАПАДНОЙ СИБИРИ
}

\author{
Крамаренко Виолетта Валентиновна', \\ kramarenko-v-v@mail.ru
}

Молоков Виктор Юрьевич',

vik3011347@vandex.ru

\author{
Абдель Азиз Эль Шинави, \\ ageoabdelaziz@vahoo.com \\ 1 Национальный исследовательский Томский политехнический университет, \\ Россия, 634050, г. Томск, пр. Ленина, 30. \\ 2 Университет Загазиг, \\ Египет, 44519, Загазиг.
}

\begin{abstract}
Актуальность. Классификация органоминеральных грунтов по государственным стандартам давно требует корректирования, так как методы определения классификационных показателей консистенции дают завышенные значения влажности границ раскатывания и текучести из-за высокого содержания органического вещества. Вследствие несовершенства стандартов испытания проводятся субъективно, их результаты малодостоверны и грунты неправильно классифицируются, что приводит к ошибкам в расчетах оснований сооружений. Целесообразность определений консистенции содержащих органику грунтов сомнительна, и в целях снижения затрат при инженерно-геологических изысканиях авторы предлагают детально рассмотреть проблему классификации органоминеральных грунтов на примере многочисленных экспериментальных данных, полученных для грунтов Западно-Сибирского региона, и рекомендуют внести изменения в действующие стандарты.

Цель: на базе экспериментальных исследований органоминеральных грунтов Западной Сибири выявить взаимосвязи между показателями консистенции и содержанием органического вещества и обосновать правомочность использования классификаций по пределам Аттерберга, применяемых для минеральных грунтов.

Объект: органоминеральные глинистые грунты, типичные для Западной Сибири, отобранные на территории окрестностей г. Томска, нефтегазовых месторождений Томской области и Ханты-Мансийского автономного округа

Методы: методы определения влажности на границе текучести и раскатывания $\left(w_{L} n W_{p}\right)$, содержания органического вещества

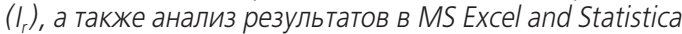

Результаты. Проведен обзор и анализ зарубежных методов определения классификационных показателей консистенции при инженерно-геологических изысканиях, рассмотрены проблемы их получения и применения для грунтов, содержащих органику. Проведены определения органического вещества, показателей влажности и консистенции, получены значимые взаимосвязи между показателями, и составлены регрессионные уравнения. В итоге выявлены несоответствия с действующей классификацией органоминеральных глинистых грунтов из-за завышения показателей консистенции, поэтому в связи с их неинформативностью рекомендуется отказаться от их применения для грунтов, содержащих органику.
\end{abstract}

\section{Ключевые слова:}

Органические и органоминеральные грунты, пределы текучести и раскатывания,

содержание органического вещества, индекс пластичности, классификация торфов и органоминеральных грунтов.

\section{Введение}

При инженерных изысканиях в районах заболоченных территорий Западной Сибири с широким развитием слабых органических и органоминеральных грунтов большое значение уделяется их классифицированию на основе оценки содержания органического вещества и показателей консистенции глинистых грунтов. Многолетняя практика работы с грунтами показала необоснованность применения классификаций глинистых грунтов по числу пластичности и показателю текучести, согласно ГОСТ 25100 [1], для грунтов органоминеральных. Поводом для статьи послужила неопределенность и неоднозначность классификаций органических и органоминеральных грунтов действующих нормативных документов, в результате чего определяются несущественные параметры для расчетов при проектировании оснований со- оружений и неоправданно завышаются объемы и стоимость работ при инженерно-геологических изысканиях, в связи с этим цель корректировки классификации весьма актуальна.

Цель работы - выявить на базе экспериментальных исследований взаимосвязи между показателями консистенции и содержанием органического вещества органоминеральных грунтов Западной Сибири, чтобы обосновать (или опровергнуть) применение для них классификаций по пределам Аттерберга.

Задачи включали научный обзор отечественных и зарубежных методик определения показателей консистенции, проблем, связанных с их применением при классифицировании органоминеральных грунтов; проведение лабораторных исследований органоминеральных грунтов разных объектов территории Западной Сибири, а также выявление за- 
висимостей между количеством органического вещества и показателями консистенции.

\section{Обзор ранее проведенных исследований}

Методики получения показателей пластичности и проблемы, связанные с процедурой их определения и дальнейшим применением, приведены в работах [1-18]. В России наиболее ранние данные о консистенции торфов приведены И.И. Вихляевым в отчете о строительстве канала Москва-Волга [2]. В работах М.П. Воларовича, С.Н. Маркова, А.А. Багрова приводятся данные по определению нижнего предела пластичности на коническом пластометре Кп-3 [3] и пенетрометрах [3-7]. И.Д. Беловидов и Н.Г. Горячкин определяли показатель пластичности торфов на кулачковом пластиметре как отношение диаметра образца после деформации $\mathrm{d}$ к его исходному диаметру $d_{n}: K=d / d_{n}$ [6]. Так как нижний предел пластичности соответствует максимальной молекулярной влагоемкости, А.Ф. Лебедевым предложены методы центрифугирования, высоких колонн, пленочного равновесия (прессования) [7, 8], основанные на удалении свободной воды и определении остаточной влажности, принимаемой за связанную. Еще два метода предложены в патентах: один основан на взаимосвязи показателей пластичности и текучести [9], второй предлагает оборудование для определения влажности «максимальной молекулярной влагоемкости" [10]. На Российском рынке отечественное оборудование для определения границы пластичности представлено следующими приборами: устройствами для автоматического определения границы пластичности методом раскатывания и методом прессования (ГТ 1.8.2 и ГТ 1.8.1 000 «НПП Геотек») по ГОСТ 5180 [12]; балансирными конусами Васильева КБВ [14] и ШПВ [15], пенетрометром грунтовым П.О. Бойченко ПБ-1Ф (ООО «РНПО «РосПрибор») [13].

Согласно ГОСТ 25100 [1], заторфованные грунты относятся к глинистым или пескам, соответственно, для определения разновидностей первых необходимо определять показатели консистенции, а для вторых - фракционный состав. Для органоминеральных грунтов из других классификаций стандарта ГОСТ 25100, по-видимому, определение этих показателей не предусмотрено, но постоянно проводится. В России, согласно ГОСТ 5180 [12], определение верхнего предела пластичности $w_{L}$ (влажности грунта на границе текучести) осуществляется методом балансирного конуса Васильева КБВ, нижнего предела пластичности $w_{P}$ (влажности грунта на границе раскатывания) - методом раскатывания, а также методом прессования под давлением 2 МПа до завершения водоотдачи грунта. Актуализация ГОСТ 5180 усложнила процедуру тестирования - дистиллированная вода должна соответствовать стандарту ГОСТ 6709 [14], по-видимому, влияние ее $\mathrm{pH}$ и УЭС на результаты определения консистенции грунтов весьма значительны. Согласно ГОСТ 21216.1-93 [15], определение верхнего предела пластичности осуществляется при помощи прибора конструкции Васильева с наконечником в виде усеченного клина, а влажности грунта на границе раскатывания $w_{P}$ - методом раскатывания.

За рубежом предел текучести $L L$ определяют методом падающего конуса по ИСО/ТC 178-92-12-2094 [17] и методом Казагранде по ASTM D-4318-2000 [18]. Предел пластичности $P L$ определяют, так же как в ГОСТ 5180 [12], методом раскатывания. Для сопоставления результатов применяется формула: $w_{L}=(L L+8,3) / 1,48$, согласно ГОСТ 25100 [1]. Приведённые в таблице Е.3.2. актуализированного ГОСТ 25100 [1] наименования тонкодисперсных органоминеральных и органических грунтов по ASTM D 2487 (ISO 14668) [16] сопоставляются с минеральными грунтами по ГОСТ 25100 [1].

Для заторфованных грунтов рекомендуется определение показателей консистенции, хотя их пластичность имеет совершенно иную природу, чем пластичность минеральных грунтов, и обусловлена наличием битумов, восков и других весьма специфических веществ. Общеизвестно, что содержание органики завышает значения показателей влажности и консистенции, но в то же время большинство классификаций рекомендует их определение, хотя дальнейшее их классифицирование теряет смысл: суглинки называются глинами, супеси суглинками или глинами, а также консистенция не совпадает с полевым описанием. Подобный вывод подтверждают работы N.B. Hobbs [19], отметившего, что высокая катионообменная способность остатков растений-торфообразователей усиливает адсорбцию грунтов и увеличивает естественную влажность (обычно в диапазоне 500-2000 \%), а также значения предела текучести [19].

A.0. Landva также отмечает, что торф и заторфованные грунты, содержащие значительное количество волокнистого материала, вряд ли имеют четко выраженные пределы текучести, определяемые по методу Казагранде [20]. В отличие от контактов трения в минеральных грунтах, связь между волокнами в торфяном материале с низким содержанием гумуса обеспечивается соединениями клеток и волокон [21], а сама жидкость попадает в поры клеток растительных остатков. Волокна имеют относительно высокую прочность при растяжении, открывая каналы для проникновения и движения жидкости. Подобное строение клеток с двухуровневой структурой микро- и макропор делает их пористыми, гибкими и сжимаемыми [22-24]. Физика и химия торфа и природа его органической матрицы оказывает важное влияние на получаемые значения пределов Аттерберга [25, 26].

Проблемы при определении показателей пластичности наиболее точно описаны в работах B.C. O’Kelly «O непригодности пределов Аттерберга для заторфованных грунтов» и «Пределы Аттерберга и торф» $[27,28]$. Как отмечает автор, определения консистенции торфа и других органических 
грунтов (осадков сточных вод, биосолидов и материалов для обработки воды) регулярно проводятся на практике при инженерных изысканиях и исследовательской работе, несмотря на серьезные проблемы пригодности для них пределов Аттерберга, неоднозначных процедур их определений и противоречивые точки зрения в литературе о ценности и значимости подобного тестирования. По мнению автора, есть принципиальные моменты, которые делают пределы Аттерберга непригодными для классификации органических и органоминеральных грунтов, структура и свойства которых существенно отличаются от минеральных из-за присутствия в составе как свежего волокнистого, так разложившегося аморфного торфа. На основе экспериментальных наблюдений O'Kelly доказывает, что испытания органоминеральных и органических материалов провести проблематично, тесты не дают существенных результатов, а полученные значения пределов пластичности не являются надежными индикаторами консистенции. Как отмечает автор, в классификациях ASTM [29], BSI [30] и многих других стандартах диапазоны предела текучести $L L$ и числа пластичности $P I$ на графике Казагранде ограничены значениями до 100/120 и $60 / 70 \%$, соответственно. Для грунтов органических и органоминеральных этих пределов не достаточно, следовательно, установленные критерии для минеральных грунтов нельзя использовать для органоминеральных $[27,28]$.

Н.Н. Морарескул также отметил, что понятие консистенции и методика определения ее показателей совершенно не применимы к торфу - у торфа волокнистая структура, внутри волокон вода, и изменение формы без изменения объема не возможно [31].

Процедура определения консистенции торфов и органоминеральных грунтов также вызывает сомнение многих авторов, проводивших подобные испытания. Landva отметил, что, как правило, значения PL следует применять только для образцов, ведущих себя как тонкодисперсные грунты во время проведения данного теста [20].

M. Long сообщает, что из-за влияния волокнистости невозможно определить показатель $L L$ торфа, используя либо чашку Казагранде, либо метод падения конуса [32]. По данным E.R. Farrell, показатель PL может быть установлен только для торфов с определенным количеством глинистой фракции [33]: небольшое содержание глины может не дать достоверных результатов [34]. A.W. Skempton и D.J. Petley [35] сообщают, что показатель $P L$ сложно определить для торфа, даже при высокой степени гумификации. Кроме того, тест, несомненно, зависит от действий оператора и поэтому субъективен. Из торфа можно сформировать слабый, губчатый или волокнистый жгут, и даже если ему придать требуемую форму с необходимыми размерами, при попытке ее раскатывания в соответствии со стандартизованной процедурой он рассыпается [36]. В этом контексте, поскольку торфяной жгут не может быть раскатан до определенно- го стандартного диаметра (т. е. 3,0 мм) по британскому стандарту [30] или 3,2 мм (1/8 дюйма) по американскому [18], материал определяется как непластичный.

Применение теста $L L$ к другим волокнистым органическим грунтам (осадкам отходов бумажной фабрики [37], осадкам сточных вод/биосолидам [38] и веществам для обработки воды [39]) также подвергается сомнению. Например,

H.K. Moo-Young и T.F. Zimmie выявили, что бумажные волокна и ткани в шламе бумажной мельницы вызвали проблемы при резке бороздки в чашке Казагранде при определении показателя текучести [37].

Особенно проблематична задача определения пределов Аттерберга для осадков сточных вод и копроса, в отчетах изыскателей называемых торфами и заторфованными грунтами. Авторам приходилось работать на нескольких объектах с подобными погребенными отложениями. На одном из них встречены отложения мощностью до 8 м, в которых содержание органики варьировало в широких пределах, поэтому были определены и показатели консистенции для органоминеральных грунтов, и степень разложения для органических.

Наиболее интересна с данной точки зрения работа А.И. Сергеева [40], в которой приводятся значения показателей консистенции для наиболее распространенных видов торфа верховых, переходных и низинных залежей. Автор отмечает, что в естественном сложении они находятся в текучем и текучепластичном состоянии; слаборазложившиеся торфа с влажностью более 1000 \% непластичны, а с увеличением степени разложения пластичность, как способность торфа изменять форму, увеличивается. В целом, отмечает автор, методика не характеризует настоящую пластичность торфа [40].

Другая проблема заключается в применении итоговых результатов определения характеристик консистенции органических и органоминеральных грунтов (их необходимости и достоверности). Как отмечает Е.Н. Богданов [41], пределы пластичности для этих грунтов не поддаются определению либо, будучи полученными с переходом на показатель текучести, не поддаются осмыслению.

Экспериментальные данные, представленные для псевдоволокнистого торфа [42] и аморфной органической глины, с $I_{r}$, равным 98,6 и $57,0 \%$, соответственно, продемонстрировали, что при определенном давлении они могут легко раскатываться в жгуты при содержании воды значительно ниже измеренных значений $P L$. Следовательно, измеренные диапазоны пластичности условны, а рассчитанные значения индекса текучести также не являются надежными индикаторами.

Hobbs пришел к выводу, что показатели пластичности торфов (там, где они могут быть получены), не информативны, так как не коррелируют с механическим поведением грунта и, следовательно, определение показателя PL не имеет смысла. Что касается предела текучести $L L$, Hobbs [19] от- 
метил, что он может быть полезным индикатором морфологии (исходная катионообменная способность зависит от типа растительного детрита) и степени гумификации, например значения $L L=800-1500$ \% типичны для верховых торфов, а 200-600 \% - для низинных залежей [19]. Однако другие классификации торфа (например, классификация L. von Post [43]) могут выполнять эту роль с большим эффектом [29].

Связи с механическими показателями и показателями консистенции у органических и органоминеральных грунтов, исходя из рекомендаций отечественных нормативов, проявляются в пределах содержания органических веществ только до $25 \%$ : значения показателей физико-механических свойств четвертичных грунтов прогнозируются при содержании $I_{r}$ менее 5 \% (п. А.2 и таблицы А.1, А.2 и А.3. Приложения А СП 22.133330-2016) [44], а характеристики органоминеральных глинистых грунтов с учетом показателя $I_{L}$ даны в только в интервалах значений $0,05 \leq_{I r} \leq 0,1$ и $0,1 \leq I_{r} \leq 0,25$ (таблица А.4 приложения А СП 22.133330-2016) [45]. Расчетные значения сопротивления в таблице Б.5 приложения Б СП 22.133330-2016 [45] даны для песков с содержанием органики до 40 \% и при степени разложения до $20 \%$ !? Степень разложения песков ставит под сомнение содержание таблицы Б.5 из-за проблематичности ее определения.

Обзор ранее проведенных исследований показал, что характеристики консистенции у органических и органоминеральных грунтов в соответствии с требованиями нормативов для глинистых грунтов определять сложно, классифицировать их по консистенции нецелесообразно, а для прогноза механических показателей их применять не рекомендуется из-за их недостоверности. Судя по действующим нормативам, связи показателей пластичности и механических свойств слабые и носят достоверный характер лишь в грунтах с небольшим содержанием органики. Подтвердить или опровергнуть вышеприведенные выводы помогут экспериментальные исследования консистенции органоминеральных грунтов одного из самых заболоченных регионов мира - Западной Сибири.

\section{Методы исследований}

Чтобы выявить взаимосвязи показателей консистенции с содержанием органического вещества для грунтов авторами были исследованы более 1000 образцов заторфованных грунтов с объектов на территориях г. Томска и нефтегазовых месторождений Томской области (Ломовое, Полуденное, Даненберговское, Двуреченское, Крапивинское, Калиновое и др.) и ХМАО (Эльгинское, Мамонтовское и др.). Опробованы грунты с глубин до 20 м, образцы представлены погребёнными отложениями торфа и заторфованных грунтов, высокозольными бурыми углями. Показатели консистенции определялись согласно ГОСТ 5180 [12], содержание органического вещества - по ГОСТ 23740 [45].
Содержание органики в образцах предварительно определялось визуально, после чего проводились испытания по регламентам действующих методик. Необходимо отметить, что не всегда цвет является индикатором органики - образцы, отобранные при обустройстве месторождений, имели светлую палевую окраску, а содержание в них органики определялось для всех образцов исходя из опыта работ на нефтепромысловых объектах в регионе.

\section{Результаты}

По полученным данным были построены графики зависимости влажности на границе текучести и влажности на границе раскатывания от содержания органического вещества отдельно для грунтов г. Томска и его окрестностей (рисунок, $a$ ) и территорий нефтегазовых месторождений (рисунок, б) из-за разных интервалов насыщения органическим веществом.

На всех графиках зависимости показателей консистенции от содержания органики отмечается стабильная положительная корреляция. Показатель $w_{L}$ имеет больший разброс и более существенный рост значений, по сравнению с $w_{p}$, что объясняется неоднородностью и разнообразием органического материала, его способностью впитывать и удерживать влагу. Минимальный разброс значений влажности на границе раскатывания, как было отмечено, предопределила выбранная авторами более точная методика прессования грунта. Во всех случаях коэффициенты корреляции имеют значения более 50, подтверждая наличие значимых связей, на основе которых получены следующие регрессионные уравнения для органоминеральных грунтов

- города Томска и его окрестностей:

$$
\begin{aligned}
& w_{L}=2,2 I_{r}+24,1(r=0,53) ; \\
& w_{p}=1,5 I_{r}+15,3(r=0,56) ;
\end{aligned}
$$

- территорий нефтегазовых месторождений ХМАО и Томской области:

$$
\begin{aligned}
& w_{L}=0,83 I_{r}+18,9(r=0,52) ; \\
& w_{p}=0,55 I_{r}+10,8(r=0,58) .
\end{aligned}
$$

Полученные регрессионные уравнения позволяют вычислить изменения значений влажности границ текучести и раскатывания с ростом органики на каждый процент и подтверждают, что для Западносибирского региона также нельзя использовать действующие классификации глинистых грунтов для грунтов, содержащих органику. Из зависимостей следует, что по консистенции супеси классифицируются как суглинки при минимальном содержании органики, а при 10-15 \% суглинки именуются глинами, и все это происходит при неизменном фракционном составе.

Анализ графика (рисунок, $a$ ) показал, что рост характеристик начинается уже при содержании органического вещества $1 \%$, поэтому предлагается принять это значение как начальное граничное для классификации органоминеральных грунтов, после 20 \% предлагается грунты называть органи- 


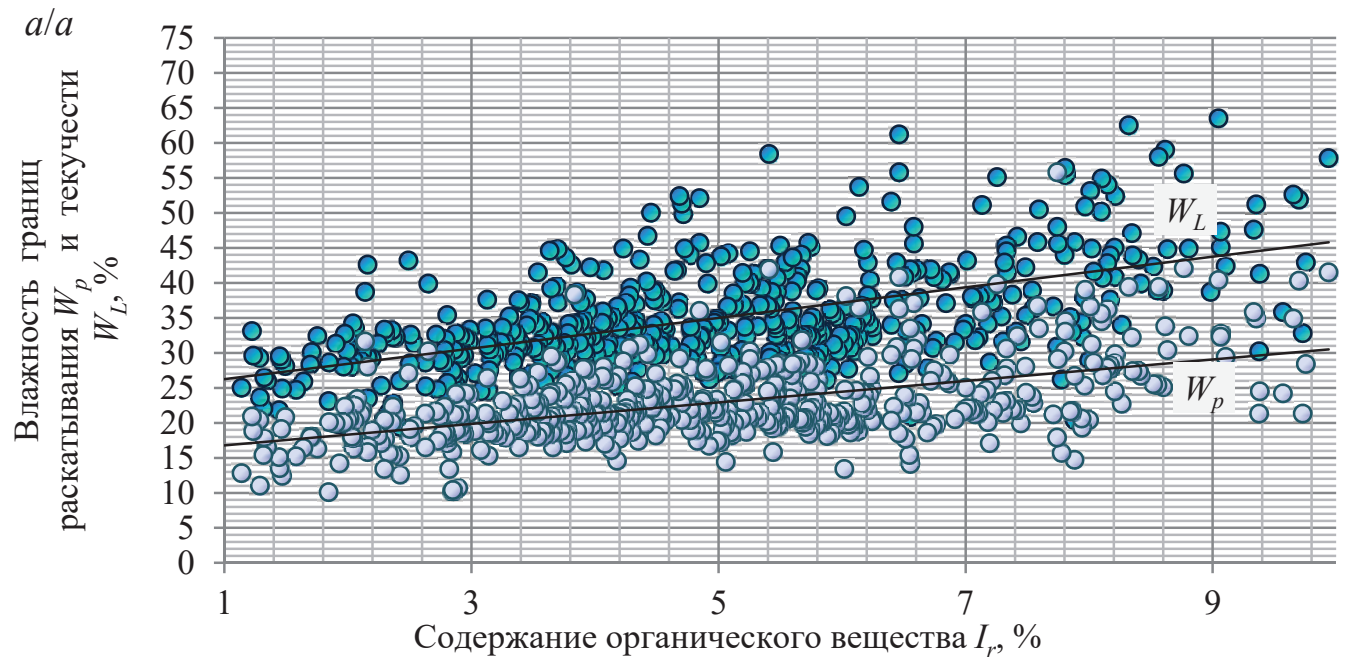

$\sigma / b$

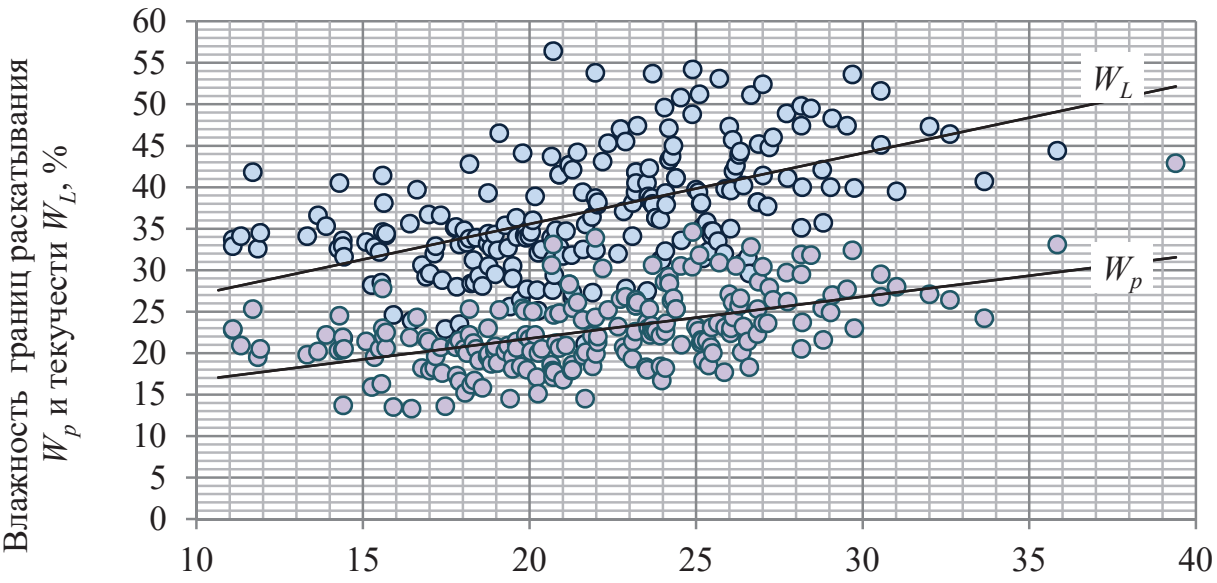

Содержание органического вещества $I_{r}, \%$

Рисунок. Зависимость влажности грании раскатывания и текучести от содержания органического вещества в грунтах территорий 2. Томска (а) и нефтегазовых месторождений (б)

Figure. Dependence of limits of liquid and plasticity on organic matter content in soils of the territories of Tomsk (a) and oil and gas fields (b)

ческими, и не классифицировать их по консистенции.

Таким образом, проведенные исследования подтвердили рост значений показателей консистенции с ростом содержания органики, в связи с этим достоверность числа пластичности и показателя текучести вызывает сомнения, как и дальнейшая классификация органоминеральных грунтов по данным показателям.

\section{Выводы}

Анализ ранее проведенных работ и многочисленные испытания авторов подтвердили, что показатели консистенции органоминеральных грунтов сложно определять в соответствии с требованием действующих стандартов, полученные результаты не надежны и неинформативны, носят субъективный характер и не позволяют правильно классифицировать грунты, так как влажность пределов текучести и раскатывания увеличивается с ростом органического вещества. В работе выявлено, что рост характеристик консистенции начинается при содержании органического вещества 1 \%, поэтому предлагается принять значение как начальное граничное для органоминеральных грунтов, классифицировать их по консистенции при содержании органики до 10 \%, или не применять для органоминеральных грунтов данную методику, что позволит значительно уменьшить объемы работ при инженерно-геологических изысканиях в заболоченных регионах. Данная работа стала первым шагом по корректировке классификации органических и органоминеральных грунтов и выбору методик определения классификационных показателей.

Исследование выполнено в Толском политехническом университете в рамках програмлы повышения конкурентоспособности Томского политехнического университета (средства ВИУ). 


\section{СПИСОК ЛИТЕРАТУРЫ}

1. ГОСТ 25100-2011. Грунты. Классификация. - М.: Стандартинформ, 2013. - 39 с.

2. Канал Москва-Волга. Торф на строительстве канала. 1932-1937 гг. - М.; Л.: Государственное издательство строительной литературы, $1940 .-189$ с.

3. Воларович М.П., Марков С.Н. Определение предельного напряжения сдвига торфа методом конического пластометра // Заводская лаборатория. - 1951. - Т. 17. - № 12 . C. $1461-1464$.

4. Воларович М.П., Багров А.А. Исследование вязкопластических свойств верхового и низинного видов торфа в широком интервале влажности / Труды КТИ. - 1960. - Вып. 11. C. $227-241$.

5. Лиштван И.И., Король Н.Т. Основные свойства торфа и методы их определения. - Минск: Наука и техника, 1975. - 319 с.

6. Беловидов И.Д., Горячкин В.Г. Классификация консистенций переработанного торфа сырца и метод определения границ нормально-пластической консистенции торфа // Труды Московского торфяного института. Вып. 8. - М.; Л.: Госэнергоиздат, 1958. - C. $35-49$.

7. РД 34.15.073-91. Руководство по геотехническому контролю за подготовкой оснований и возведением грунтовых сооружений в энергетическом строительстве. - Л.: ВНИИГ им. Б.Е. Веденеева. 1991. - 421 с.

8. Лабораторные работы по грунтоведению. Изд. 3-е испр. и доп. / под ред. В.Т. Трофимова, В.А. Королёва. - М.: КДУ, 2017. $654 \mathrm{c}$.

9. Способ определения границы раскатывания глинистых грунтов: пат. Рос. Федерация № 2305284; заявл. 20.03.2007; опубл. 27.08.2007, Бюл. № 24.

10. Способ определения границы раскатывания глинистых грунтов: пат. Рос. Федерация № 2453840; заявл. 29.07.2009; опубл. 20.06.2012. Бюл. № 48 .

11. Смоляницкий Л.А. Ускоренный способ определения границы раскатывания грунта // Вестник Воронежского Государственного Университета. Геология. - 2007. - Т. № 2. - С. 195-200.

12. ГОСТ 5180-16 Грунты. Методы лабораторного определения физических характеристик. - М.: Стандартинформ, 2016. $18 \mathrm{c.}$

13. РИ 06-2015 Методы лабораторной пенетрации. - СПб.: Открытое акционерное общество «Трест геодезических работ и инженерных изысканий», 2015. - 18 с.

14. ГОСТ 6709-72. Вода дистиллированная. Технические условия. - М.: Стандартинформ, 1972. - 12 с.

15. ГОСТ 21216.1-93. Сырье глинистое. Метод определения пластичности. - М.: Стандартинформ, 1993. - 6 с.

16. ASTM D 2487-17: Standard practice for classification of soils for engineering purposes (Unified Soil Classification). - West Conshohocken, PA: ASTM International, 2017. URL: https://www. astm.org/Standards/D2487.htm (дата обращения 14.07.2018).

17. PKN CEN ISO/TS 17892-1:2009. ISO 17892-12:2018 Geotechnical investigation and testing. Laboratory testing of soil. P. 12: Determination of liquid and plastic limits. URL: https://www.iso.org/standard/72017.html (дата обращения 14.07.2018).

18. ASTM D4318 - 17e1: Standard Test Methods for Liquid Limit, Plastic Limit, and Plasticity Index of Soils. West Conshohocken, PA: ASTM International, 2017. URL: https://www.astm. org/Standards/D4318.htm (дата обращения 14.07.2018).

19. Hobbs N.B. Mire morphology and the properties and behaviour of some British and foreign peats // Quarterly Journal of Engineering Geology. - 1986. - V. 19. - P. 7-80.

20. Structures on peatland - geotechnical investigations / A.0. Landva, P.E. Pheeney, P. La Rochelle, J.L. Briaud // Proceedings of the Advances in Peatlands Engineering Conference. - Ottawa, Canada: National Research Council of Canada, 1986. - P. 31-52.
21. Adams J.I. A comparison of field and laboratory measurements in peat // Proc. Ninth Muskeg Research Conf. and Ontario HydroResearch. - Canada, 1963. - V. 15. - P. 1-7.

22. Berry P.L., Poskitt T.J. The consolidation of peat // Geotechnique. - 1972. - V. 22 (1). - P. 25-52.

23. Dhowian A.W., Edil T.B. Consolidation behavior of peats // Geotech. Test. J. - 1980. - V. 3 (3). - P. 105-114.

24. Asadi A., Huat B.B.K., Hanafi M.M., Mohamed T.A., Shariatmadari N. Chemico-geomechanical sensitivities of tropical peat to pore fluid $\mathrm{pH}$ related to controlling electrokinetic environment // Journal of the Chinese Institute of Engineers. - 2011. V. 34 (4). - P. 481-487.

25. Yang J., Dykes A.P. The liquid limit of peat and its application to the understanding of Irish blanket bog failures // Landslides. 2006. - V. 3 (3). - P. 205-216.

26. Hobbs N.B. Mire morphology and the properties and behaviour of some British and foreign peats // Quarterly Journal of Engineering Geology. - 1986. - V. 19 (1). - P. 7-80.

27. O'Kelly B.C. Atterberg limits and peat // Environmental Geotechnics. - 2014. URL: http://dx.doi.org/10.1680/envgeo. 15.00003 (дата обращения 14.07.2018).

28. 0'Kelly B.C. Atterberg limits are not appropriate for peat soils // Environmental Geotechnics. -2015. URL: https://www.researchgate.net/publication/287973227_Atterberg_limits_are_ not_appropriate_for_peat_soils (дата обращения 14.07.2018).

29. ASTM D2487-17, Standard Practice for Classification of Soils for Engineering Purposes (Unified Soil Classification System). West Conshohocken, PA: ASTM International, 2017. URL: https://www.astm.org/Standards/D2487.htm (дата обращения 14.07.2018).

30. BSI (British Standards Institution). Methods of Test for Soils for Civil Engineering Purposes classification tests, BS1377: P. 2. Milton Keynes, UK: British Standards Institution, 1990 - 110 p.

31. Морарескул Н.Н. Основания и фундаменты в торфяных грунтах. - Л.: Стройиздат, Ленингр. отд-ние, 1979. - 80 с.

32. Long M., Boylan N. In-situ testing of peat - a review and update on recent developments // Geotechnical Engineering Journal of the SEAGS \& AGSSEA. - 2012. - V. 43 (4). - P. 41-45.

33. Farrell E.R. Organics/Peat Soils // ICE Manual of Geotechnical Engineering. V. 1 / Eds. J. Burland, T. Chapman, H. Skinner, M. Brown. - London: ICE Publishing, 2012. - P. 463-479.

34. Whitlow R. Basic Soil Mechanics. $4^{\text {th }}$ ed. - London: Pearson Education, 2001. $-592 \mathrm{p}$.

35. Skempton A.W., Petley D.J. Ignition loss and other properties of peats and clays from Avonmouth, King's Lynn and Cranberry Moss // Gèotechnique. - 1970. - V. 20 (4). - P. 343-356.

36. New technique assessment of plastic limit of soft clay particularly peat soils / R. Adon, N. Yasufuku, R. Ishikura, D. Wijeyeseke$\mathrm{ra} / /$ Memoirs of the Faculty of Engineering, Kyushu University (Fukuoka, Japan). - 2013. - V. 73 (1). - P. 47-55.

37. Moo-Young H.K., Zimmie T.F. Geotechnical properties of paper mill sludges for use in landfill covers // Journal of Geotechnical Engineering ASCE. - 1996. - V. 122 (9). - P. 768-776.

38. O’Kelly B.C., Zhang L. Consolidated-drained triaxial compression testing of peat // Geotechnical Testing Journal. - 2013. V. 36 (3). - P. $310-321$.

39. 0'Kelly B.C. Characterisation and undrained strength of amorphous clay // Proceedings of the Institution of Civil Engineers Geotechnical Engineering. - 2014. - V. 167 (3). - P. 311-320. URL: http://dx.doi.org/10.1680/geng.11.00025 (дата обращения 14.07.2018).

40. Сергеев А.И. Методика инженерно-геологического изучения торфяных массивов. - М.: Наука, 1974. - 126 с

41. Богданов Е.Н. 0 физико-механических свойствах заторфованных грунтов торфов // Грунтоведение. - 2014. - № 2. - С. 43-52.

42. Zhang L., O'Kelly B.C. The principle of effective stress and triaxial compression testing of peat // Proceedings of the Institu- 
tion of Civil Engineers - Geotechnical Engineering. - 2014. V. 167 (1). - P. 40-50. URL: http://dx.doi.org/10.1680/geng. 12.00038 (дата обращения 14.07.2018).

43. Von Post L. Sveriges Geologiska Undersoknings torvinventering och nogra av dess hittils vunna resultat (SGU peat inventory and some preliminary results). - Sweden, Jonkoping: Svenska Mosskulturforeningens Tidskrift, 1922. - P. 1-37.
44. СП 22.133330-2016. Основания зданий и сооружений. Актуализированная редакция взамен СНиП 2-02.01-83 - М.: НИИОСП им.Н.М.Герсеванова, 2016. - 225 с.

45. ГОСТ 23740-2016 Методы определения содержания органических веществ - М.: Стандартинформ, 2016. - 18 с.

Поступила 14.05.2019 2.

\section{Информация об авторах}

Крамаренко В.B., кандидат геолого-минералогических наук, доцент отделения геологии Инженерной школы природных ресурсов Национального исследовательского Томского Политехнического университета.

Молоков В.Ю., ассистент отделения нефтегазового дела Инженерной школы природных ресурсов Национального исследовательского Томского Политехнического университета.

Шинави A.Э., кандидат геолого-минералогических наук, доцент кафедры инженерной и экологической геологии Факультета естественных наук Университета Загазиг. 
UDC 624.131

\title{
CLASSIFICATION ON CONSISTENCY OF ORGANOMINERAL SOILS OF WESTERN SIBERIA
}

\author{
Violetta V. Kramarenko', \\ kramarenko-v-v@mail.ru \\ Viktor Yu. Molokov', \\ vik3011347@yandex.ru
}

\author{
Abdel Aziz El Shinawi², \\ ageoabdelaziz@yahoo.com \\ 1 National Research Tomsk Polytechnic University, \\ 30, Lenin Avenue, Tomsk, 634050, Russia. \\ 2 Zagazig University, \\ 44519 Zagazig, Egypt.
}

Relevance. Classification of organomineral soils according to state standards require correction. Methods for determining classification consistency indicators give excessive values moisture content of the plasticity and liquid limits due to the high content of organic matter. Due to imperfect standards, their results are unreliable and the grounds are incorrectly classified, which leads to errors in calculations of the base of constructions. The expediency of determining the consistency of organics containing soils is doubtful, and in order to reduce costs in engineering and geological investigations, the authors propose to consider in detail the problem of classification of organomineral soils by the example of numerous experimental data obtained for soils in the West Siberian region and recommend the changes to existing standards.

The main aim of the research is to identify the relationship between consistency indicators and organic matter content based on the experimental studies of organic-mineral soils of Western Siberia and justify the use of the Atterberg limits applied for mineral soils.

object: organomineral clay soils typical for Western Siberia, picked on the territory surroundings of the city of Tomsk, oil and gas fields of Tomsk region and Khanty-Mansiysky Autonomous District.

Research methods include a method for determining limits of liquid and plasticity ( $W_{L}$ and $W_{P}$ ) and organic content $\left(I_{r}\right)$, as well as by analyzing the results using MS Excel and Statistica.

Results. The authors have carried out the review and analysis of foreign methods for determining the classification indexes of consistency in engineering-geological surveys and considered the problems of their carrying out and applications for soils containing organic substances. The determinations of organic matter, moisture content and consistency were carried out, significant interrelations between the indices were obtained and regression equations were compiled. As a result, inconsistencies with the current classification of organomineral clay soils due to overestimation of the consistency indices are revealed, therefore, in relation to their uninformativeness, it is recommended to abandon their use for organics containing soils.

\section{Key words:}

Organic and organomineral soils, liquid and plasticity limits, organic content, plasticity index, classification of peats and organomineral soils.

The research was carried out at Tomsk Polytechnic University within the Competitiveness Enhancement Program of Tomsk Polytechnic University (VIUfunds).

\section{REFERENCES}

1. GOST 25100-2011. Grunty. Klassifikatsiia [State Standard 25100-2011. Soils. Classification]. Moscow, Standartinform Publ., 2013. 39 p.

2. Vikhlyaev I.I. Kanal Moskva-Volga. Torf na stroitelstve kanala. 1932-1937 [Channel Moscow-Volga. Peat in the construction of the canal. 1932-1937]. Leningrad, Gosudarstvennoe izdatelstvo stroitelnoy literatury Publ., 1940. $189 \mathrm{p}$.

3. Volarovich M.P., Markov S.N. Opredelenie predelnogo napryazheniya sdviga torfa metodom konicheskogo plastometra [Determination of the maximum shear stress of peat by a conical plastometer]. Zavodskaia laboratoriya, 1951, vol. 17, no. 12, pp. 1461-1464.

4. Volarovich M.P., Bagrov A.A. Issledovanie vyazkoplasticheskikh svoystv verkhovogo i nizinnogo vidov torfa v shirokom intervale vlazhnosti [Study of visco-plastic properties of upper and lower peat species in a wide range of humidity]. Trudy KTI, 1960, Iss. 11 , pp. 227-241.

5. Lishtvan I.I., Korol N.T. Osnounye svoystva torfa i metody ikh opredeleniya [Main properties of peat and methods of their definition]. Minsk, Nauka i tekhnika Publ., 1975. 319 p.
6. Belovidov I.D., Goriachkin V.G. Klassifikatsiya konsistentsiy pererabotannogo torfa syrtsa i metod opredeleniya granits normalno-plasticheskoy konsistentsii torfa [Classification of raw processed peat consistencies and method of determining the boundaries of normal plastic peat consistency]. Trudy Moskovskogo torfyanogo instituta [Proceedings of Moscow Peat Institute]. Leningrad, Gosenergoizdat Publ., 1958. pp. 35-39.

7. RD 34.15.073-91 Rukovodstvo po geotekhnicheskomu kontrolyu za podgotovkoy osnovaniy i vozvedeniem gruntovykh sooruzheniy $v$ energeticheskom stroitelstve [RD 34.15.073-91 Guidelines for geotechnical control of Foundation preparation and construction of ground structures in power engineering]. Leningrad, B.E. Vedeneev VNIIG Publ, 1991. 427 p.

8. Korolev V. A., Trofimov V.T., Samarin E.N. Laboratornye raboty po gruntovedeniyu. [Laboratory works on soil science]. Moscow, KDU Publ., 2017. 654 p.

9. Ermolaeva A.N., Sokurov V.V., Ivanov A.A. Sposob opredeleniya granitsy raskatyvaniya glinistykh gruntov [Method for determining the boundary of rolling clay soils]. Patent RF, no. 2305284, 2007. 
10. Kalbergenov R.G., Kutergin V.N., Novikov P.I., Frolov S.I. Sposob opredeleniya granitsy raskatyvaniya glinistykh gruntov [Method for determining the boundary of rolling clay soils]. $\mathrm{Pa}$ tent RF, no. 2453840, 2009.

11. Smolyanitskiy L.A. Accelerated method for determining the boundary of soil rolling. Bulletin of Voronezh state University. Geology, 2007, vol. 2 pp. 195-200. In Rus.

12. GOST 5180-16. Grunty. Metody laboratornogo opredeleniya fizicheskikh kharakteristik [State Standard 5180-16. Soils. Methods of laboratory determination of physical characteristics.]. Moscow, Standartinform Publ., 2016. 18 p.

13. RI 06-2015. Metody laboratornoy penetratsii [Working instruction 06-2015. Methods of laboratory penetration]. St-Petersburg, Trest geodezicheskikh rabot i inzhenernykh izyskaniy Publ.., 2018. 18 p.

14. GOST 6709-72. Voda distillirovannaya. Tekhnicheskie usloviya [State Standard 6709-72. Water distilled. Technical conditions.]. Moscow, Standartinform Publ., 1972.12 p.

15. GOST 21216.1-93. Syre glinistoe. Metod opredeleniya plastichnosti [State Standard 21216.1-93. Raw clay. Method for the determination of plasticity.]. Moscow, Standartinform Publ., 1993. $6 \mathrm{p}$.

16. ASTM D 2487-17: Standard practice for classification of soils for engineering purposes (Unified Soil Classification). West Conshohocken, PA, ASTM International, 2017. Available at: https:// www.astm.org/Standards/D2487.htm (accessed 14 July 2018).

17. PKN CEN ISO/TS 17892-1:2009. ISO 17892-12:2018 Geotechnical investigation and testing - Laboratory testing of soil. P. 12: Determination of liquid and plastic limits. Available at: https://www.iso.org/standard/72017.html (accessed 14 July 2018).

18. ASTM D4318 - 17e1: Standard Test Methods for Liquid Limit, Plastic Limit, and Plasticity Index of Soils. West Conshohocken, PA, ASTM International, 2017. Available at: https://www. astm.org/Standards/D4318.htm (accessed 14 July 2018).

19. Hobbs N.B. Mire morphology and the properties and behaviour of some British and foreign peats. Quarterly Journal of Engineering Geology, 1986, vol. 19, pp. 7-80.

20. Landva A.O., Pheeney P.E., La Rochelle P., Briaud J.L. Structures on peatland - geotechnical investigations. Proceedings of the Advances in Peatlands Engineering Conference. Ottawa, Canada, National Research Council of Canada, 1986. pp. 31-52.

21. Adams J.I. A comparison of field and laboratory measurements in peat. Proc. Ninth Muskeg Research Conf. and Ontario HydroResearch. Canada, 1963. Vol. 15, pp. 1-7.

22. Berry P.L., Poskitt T.J. The consolidation of peat. Geotechnique, 1972, vol. 22 (1), pp. 25-52.

23. Dhowian A.W., Edil T. B. Consolidation behavior of peats. Geotech. Test.J., 1980, vol. 3 (3), pp. 105-114.

24. Asadi A., Huat B.B.K., Hanafi M.M., Mohamed T.A., Shariatmadari N. Chemico-geomechanical sensitivities of tropical peat to pore fluid $\mathrm{pH}$ related to controlling electrokinetic environment. Journal of the Chinese Institute of Engineers, 2011, vol. 34 (4), pp. 481-487.

25. Yang J., Dykes A.P. The liquid limit of peat and its application to the understanding of Irish blanket bog failures. Landslides, 2006, vol. 3 (3), pp. 205-216.

26. Hobbs N.B. Mire morphology and the properties and behaviour of some British and foreign peats. Quarterly Journal of Engineering Geology, 1986, vol. 19 (1), pp. 7-80.

27. 0'Kelly B.C. Atterberg limits and peat. Environmental Geotechnics, 2014. Available at: http://dx.doi.org/10.1680/envgeo. 15.00003 (accessed 14 July 2018).

28. 0'Kelly B.C. Atterberg limits are not appropriate for peat soils. Environmental Geotechnics, 2015. Available at: https://www. researchgate.net/publication/287973227_Atterberg limits are_not_appropriate_for_peat_soils (accessed 14 July 2018).
29. ASTM D2487-17, Standard Practice for Classification of Soils for Engineering Purposes (Unified Soil Classification System). West Conshohocken, PA, ASTM International, 2017. Available at: https://www.astm.org/Standards/D2487.htm (accessed 14 July 2018).

30. BSI (British Standards Institution). Methods of Test for Soils for Civil Engineering Purposes (Shear Strength Tests: Total Stress), BS1377. P. 7. Milton Keynes, UK, British Standards Institution, $1990.110 \mathrm{p}$.

31. Morareskul H.H. Osnovaniya i fundamenty v torfyanykh gruntakh [Bases and foundations in peat soils]. Leningrad, Stroyizdat Publ., 1979. $80 \mathrm{p}$.

32. Long M., Boylan N. In-situ testing of peat - a review and update on recent developments. Geotechnical Engineering Journal of the SEAGS \& AGSSEA, 2012, vol. 43 (4), pp. 41-45.

33. Farrell E.R. Organics/Peat Soils. ICE Manual of Geotechnical Engineering. Eds. J. Burland, T. Chapman, H. Skinner, M. Brown. London, ICE Publ., 2012. Vol. 1, pp. 463-479.

34. Whitlow R. Basic Soil Mechanics. $4^{\text {th }}$ ed. London, Pearson Education, 2001. $592 \mathrm{p}$

35. Skempton A.W., Petley D.J. Ignition loss and other properties of peats and clays from Avonmouth, King's Lynn and Cranberry Moss. Geotechnique, 1970, vol. 20 (4), pp. 343-356. Available at: http:// dx.doi.org/10.1680/geot.1970.20.4.343 (accessed 14 July 2018).

36. Adon R., Yasufuku N., Ishikura R., Wijeyesekera D. New technique assessment of plastic limit of soft clay particularly peat soils. Memoirs of the Faculty of Engineering, Kyushu University (Fukuoka, Japan), 2013, vol. 73 (1), pp. 47-55.

37. Moo-Young H.K., Zimmie T.F. Geotechnical properties of paper mill sludges for use in landfill covers. Journal of Geotechnical Engineering ASCE, 1996, vol. 122 (9), pp. 768-776.

38. O'Kelly B.C., Zhang L. Consolidated-drained triaxial compression testing of peat. Geotechnical Testing Journal, 2013, vol. 36 (3), pp. 310-321.

39. O'Kelly B.C. Characterisation and undrained strength of amorphous clay. Proceedings of the Institution of Civil Engineers Geotechnical Engineering, 2014, vol. 167 (3), pp. 311-320. Available at: http://dx.doi.org/10.1680/geng.11.00025 (accessed 14 July 2018).

40. Sergeev A.I. Metodika inzhenerno-geologicheskogo izucheniya torfianykh massivou [Methods of engineering-geological study of peat massifs]. Moscow, Nauka Publ., 1974. 126 p.

41. Bogdanov E.N. 0 fiziko-mekhanicheskikh svoystvakh zatorfovannykh gruntov torfov [About physical and mechanical properties of the ground peat]. Gruntovedenie, 2014, no. 2, pp. 43-52.

42. Zhang L., O'Kelly B.C. The principle of effective stress and triaxial compression testing of peat. Proceedings of the Institution of Civil Engineers - Geotechnical Engineering, 2014, vol. 167 (1), pp. 40-50. Available at: http://dx.doi.org/10.1680/geng. 12.00038 (accessed 14 July 2018).

43. Von Post L. Sveriges Geologiska Undersoknings torvinventering och nogra av dess hittils vunna resultat [SGU peat inventory and some preliminary results]. Jonkoping, Sweden, Svenska Mosskulturforeningens Tidskrift, 1922. pp. 1-37.

44. SP 22.133330-2016. Osnovaniya zdaniy i sooruzheniy. Aktualizirovannaya redaktsiya vzamen SNiP 2-02.01-83 [Set of rules 22.133330-2016. Bases of buildings and structures. Updated version instead of Building codes and regulations 2-02.01-83]. Moscow, NIIOSP im. N.M. Gersevanova Publ., 2016. 225 p.

45. GOST 23740-2016 Metody opredeleniya soderzhaniya organicheskikh veshchestu [State Standard 23740-2016 Methods for determination of organic matter]. Moscow, Standartinform Publ., 2016. 18 p.

Received: 14 May 2019. 


\section{Information about the authors}

Violetta V. Kramarenko, Cand. Sc., associate professor, National Research Tomsk Polytechnic University.

Victor Yu. Molokov, senior laboratory assistant, National Research Tomsk Polytechnic University.

Abdelaziz El Shinawi, PhD, associate professor of engineering and environmental geology, Zagazig University. 